Original Research Article

\title{
Knowledge, awareness and attitude regarding WHO recommended ANC visits among pregnant women attending antenatal clinic at D.Y. Patil hospital, Kolhapur, Maharashtra, India
}

\author{
Archana G. Dhavalshankh" ${ }^{1 *}$, Ganesh P. Dhavalshankh², Abhishek Dixit ${ }^{1}$
}

\begin{abstract}
${ }^{1}$ Department of Pharmacology, D.Y. Patil Medical College, Kolhapur, Maharashtra, India ${ }^{2}$ Department of Dermatology, Rajarshee Chatrapati Shahu Maharaj Government Medical College, Kolhapur, Maharashtra, India
\end{abstract}

Received: 16 January 2019 Accepted: 05 March 2019

\section{*Correspondence to: Dr. Archana G. Dhavalshankh, Email: archana9595@ yahoo.com}

Copyright: (C) the author(s), publisher and licensee Medip Academy. This is an openaccess article distributed under the terms of the Creative Commons Attribution NonCommercial License, which permits unrestricted noncommercial use, distribution, and reproduction in any medium, provided the original work is properly cited.

\begin{abstract}
Background: ANC is the care woman receives throughout the pregnancy in order to ensure that both the mother and child remain healthy. Promotion of maternal and child health is the most important component of family welfare programme of Govt. of India. It is useful to promote, prevent and protect maternal and perinatal health for the sustainable growth and development of country. Unfortunately, many women in developing countries do not receive such care. This study is conducted to identify, address and to assess the awareness and knowledge about own health during pregnancy and to improve maternal health, to improve maternal health services and to limit barriers among health systems working at all levels.

Methods: This study is done in D.Y. Patil Hospital, Kolhapur among pregnant women attending ANC from April to June 2017. A questionnaire was used to collect data and assessed in either positive or negative response. Statistical analysis was done in terms of percentage.

Results: During the analysis $48.1 \%$ had knowledge about ANC check-ups and $26.7 \%$ admitted about the importance of ANC check-up and visits. Regarding awareness, $35.8 \%$ were aware about the importance of ANC card, 28.3\% were aware about the parameters, check-ups and investigations. $23 \%$ agreed that each ANC visit can improve the health and baby's growth, while evaluating Attitude $32.6 \%$ enquired about their improvement or complications they will have to face. Conclusions: Present study data is baseline but informative for further planning of health in intervention programme. It is also useful for enhancing awareness of antenatal care and for motivating the women to utilize maternal care services.
\end{abstract}

Keywords: Awareness, Attitude, Antenatal care, ANC visits, Knowledge

\section{INTRODUCTION}

ANC is the care of woman during the pregnancy in order to ensure that both the mother and child remain healthy. Promotion of maternal health and child health is one of the most important components of World Health Organization under family welfare programme in India. ${ }^{1}$ It is useful to decrease child and maternal mortality and morbidity and to promote, prevent and protect maternal and perinatal health for sustainable improvement in growth and development of country. Unfortunately, many women in developing countries do not receive such care. ${ }^{2}$
Appropriate antenatal care (ANC) is one of the pillars of maternal and perinatal health. Antenatal care is considered as a backbone of obstetrical services and health of pregnant women. It includes not only providing nutrition and care but also detection and management of maternal and fetal complications during ANC period. ${ }^{3}$ It highlights the care of antenatal mothers as an important tool in maternal healthcare as appropriate care will lead to successful pregnancy outcome and healthy babies. Safe motherhood by providing good antenatal care (ANC) is very important to reduce maternal mortality ratio and infant mortality rate and to achieve millennium development goals. 
According to Ojo, ANC services are provided to a pregnant woman at monthly intervals, to 28 weeks of gestation, then fortnightly until 36 weeks and finally weekly visit until the birth of the baby. ${ }^{2}$ Similarly, According to Adesokan FO, antenatal services means the attention, education, supervision and treatment given to the pregnant women from the time conception is confirmed until the beginning of labour, in order to ensure safe pregnancy, labour and puerperium. ${ }^{4}$ It's very important to provide qualitative antenatal services by a skilled or trained health provider to pregnant women to promote the health and survival of mother and child. Ekabua et al, state that the focused antenatal services should have minimum number of antenatal clinic visits but each of which has specific items of pregnancy assessment, education and care to ensure early detection and prompt management of complication. ${ }^{5}$

All pregnant women are at risk of developing complication, but more attention is required in the highrisk group and approach to antenatal services with skilled healthcare provider. Average knowledge, minimum awareness and positive attitude towards ANC is also important aspect of ANC programme. The knowledge as information, understanding and skills that one gains through education or experience.

Hornby AS, describes that inadequate knowledge concerning health related matters usually lead to negative attitude towards the health issue and Igbokwe CC, states that attitude is the person's affective feelings of like and dislike. ${ }^{6,7}$ Maximum number of pregnant women are unaware of their health, hygiene, foetal care, visits to health centres, regularity of ANC check-ups. This study is conducted to assess the knowledge of pregnant woman about ANC registration, card, visit, check-up and it's importance. Study conducted to find out the awareness of pregnant women about ANC visits and to know the attitude of pregnant women regarding ANC visits and health check-up.

\section{METHODS}

This prospective, observational study was conducted in D.Y. Patil Medical College, Kolhapur, Maharashtra, India in 2018. This study employed a qualitative research method. Such methods are appropriate when the core objective is to explore behaviour rather than to describe it. The research approach was accordingly evaluative to that extent. All women who were attending antenatal OPD in D.Y. Patil Hospital and who were willing to participate in this study were included in the study. All the eligible participants were interviewed using a structured questionnaire which included socio-demographic profile and questions pertaining to knowledge, awareness and attitude regarding ANC and check-ups. Informed written consent was taken from each participant. A total 200 women interviewed, out of which 187 gave written consent while 13 were not ready for written consent therefore excluded from the study.
Women were asked 15 structured questions in vernacular language related to the Knowledge, Awareness \& Attitude of the woman about ANC check-up and asked to mark it, the result was assessed in either positive or negative response to the questions. Statistical analysis was done as descriptive method in terms of percentage. The Study was conducted after approval of Institutional Ethics Committee.

\section{RESULTS}

In present study as shown in Table 1, among 200 interviewed women, total 187 women were ready to participate in the study and that was done in 3 months period during which we assessed women in age range of 21 to 35 years. Among 187, $108(57.7 \%)$ was from the age group of 21 to 25 years and $79(32.3 \%)$ was from the age group 26-35 years of age. Out of 187 respondents, 102 $(54.5 \%)$ were at the level of primary, $61(32.6 \%)$ were at the level of secondary, $22(11.8 \%)$ at graduate and $2(1.1 \%)$ at postgraduate level of education. Among 187, about 146 $(78 \%)$ of them were housewives while $41(22 \%)$ of them are working women. From 187 women, 127(68\%) were primigravida and $60(32 \%)$ were multipara. Among multipara only $3(5 \%)$ were home delivery and $57(95 \%)$ were hospital delivery. In the reproduction history of 60 multipara, $11(18.3 \%)$ had experienced episode of eclampsia, $14(23.3 \%)$ had perineal tear, only $1(1.66 \%)$ of them had history of one stillbirth before while 20 (33.3\%) of the interviewed women had history of postpartum haemorrhage. Out of 187, $155(83 \%)$ attended antenatal clinic at 12 weeks and $29(15 \%)$ at 28 weeks while only 3 $(1.6 \%)$ at full term of gestation so $122(65 \%)$ were visiting regularly and $65(35 \%)$ were late visitors as per scheduled programme.

In present study, Figure I- show, the interviewed women's responses to the question on knowledge, awareness and attitude regarding antenatal care. There were 5 questions each on knowledge, awareness and attitude. Further analysis of the questions on knowledge revealed that 120 (64.1\%) women know about ANC card, 115 (61.5\%) about registration number, $85(45.5 \%)$ about of ANC visits, 90 (48.1\%) had knowledge about ANC check-ups and 50 (26.7\%) admitted knowing importance ANC check-up and visits. Regarding awareness, we interviewed 5 questions in which $67(35.8 \%)$ women were aware about the importance of bringing the ANC card during every visit, 53 (28.3\%) women were aware about the parameters, Check-ups and investigations done during each visit, 43 (23\%) women agreed that each ANC visit can improve their health and baby's growth, 35 (18.7\%) agreed that each visit is helpful to identify complications in advance and measures can be taken to prevent it, but only $28(15 \%)$ women were aware about the new implementations by Indian Government about the increased ANC visits and check-up by Specialists during their visit on 9th day of every month. For evaluating Attitude on ANC, we interviewed women with 5 questions and found that $68(36.4 \%)$ women were bringing ANC card regularly, $62(33.2 \%)$ observing the markings of the visit 
date and other details about check-up and remarks on the card, $53(28.3 \%)$ women completed the scheduled visit and health check-ups of ANC, 61 (32.6\%) women enquired about the improvement or complications regarding health of the mother and baby with health personnel and 51 (27.3\%)women were satisfied with the ANC visits, checkups and facilities given.

Table 1: Association of knowledge, awareness and attitude between various parameters in ANC respondents.

\begin{tabular}{|c|c|c|c|c|c|c|c|c|}
\hline \multirow{2}{*}{ Sr. No. } & \multirow{2}{*}{ Parameter } & \multirow{2}{*}{$\begin{array}{l}\text { Frequency } \\
\text { Percentage }\end{array}$} & \multicolumn{2}{|l|}{ Knowledge } & \multicolumn{2}{|l|}{ Awareness } & \multicolumn{2}{|l|}{ Attitude } \\
\hline & & & Good & Poor & Present & Absent & Positive & Negative \\
\hline \multirow{2}{*}{ Age } & 21- 24 years & $108(57.7 \%)$ & $89(82.4 \%)$ & $19(17.6 \%)$ & $87(80.5 \%)$ & $21(19.5 \%)$ & $100(92.5 \%)$ & $08(7.5 \%)$ \\
\hline & 25-35 years & $79(32.3 \%)$ & $66(83.5 \%)$ & $13(16.5 \%)$ & $63(79.7 \%)$ & $16(20.3 \%)$ & $66(83.5 \%)$ & $13(16.5 \%)$ \\
\hline \multirow{5}{*}{ Education } & Uneducated & 00 & - & - & - & - & - & - \\
\hline & Primary & $102(54.5 \%)$ & $77(75.5 \%)$ & $25(24.5)$ & 75( & $27(26.5 \%)$ & $75(73.5 \%)$ & $27(26.5 \%)$ \\
\hline & Secondary & $61(32.7 \%)$ & $59(96.7 \%)$ & $02(3.3 \%)$ & $.8 \%)$ & $05(8.2 \%)$ & $60(98.3 \%)$ & $01(1.7 \%)$ \\
\hline & Graduate & 22( & $21(95.5 \%)$ & $01(4.5 \%)$ & $0 \%)$ & - & $22(100 \%)$ & - \\
\hline & Posts & 02( & $02(100 \%)$ & - & 02 & - & $00 \%)$ & - \\
\hline \multirow{2}{*}{ Occupation } & Wor & 146 & $134(91.8 \%)$ & $2 \%)$ & $144(98.6 \%)$ & 02 & $144(98.6 \%)$ & $02(1.4 \%)$ \\
\hline & Hous & 41( & $29(70.7 \%)$ & $9.3 \%)$ & $0.4 \%)$ & $9.6 \%)$ & $39(95.1 \%)$ & $02(4.9 \%)$ \\
\hline \multirow{2}{*}{ Para } & & $127(68 \%)$ & $119(93.7 \%)$ & $08(6.3 \%)$ & $123(96.8 \%)$ & $04(3.2 \%)$ & $127(100 \%)$ & - \\
\hline & Multi & 6003 & $53(88.3 \%)$ & $07(11.7 \%)$ & $60(100 \%)$ & - & $60(100 \%)$ & - \\
\hline \multirow{2}{*}{$\begin{array}{l}\text { Place of } \\
\text { delivery }\end{array}$} & & & $03(100 \%)$ & - & - & $0 \%)$ & $02(66.7 \%)$ & $3.3 \%)$ \\
\hline & Hospital & $57(9$ & $55(96.5 \%)$ & $02(3.5 \%)$ & $55(96.5 \%)$ & $02(3.5 \%)$ & $55(96.5 \%)$ & $02(3.5 \%)$ \\
\hline \multirow{2}{*}{$\begin{array}{l}\text { Previous } \\
\text { reproductive } \\
\text { history }\end{array}$} & No mishaps & $14(23.3 \%)$ & $12(85.7 \%)$ & $02(14.3 \%)$ & $12(85.7 \%)$ & $02(14.3 \%)$ & $12(85.7 \%)$ & $02(14.3 \%)$ \\
\hline & Mishaps & $46(76.6 \%)$ & $40(87 \%)$ & $06(13 \%)$ & $42(91.3 \%)$ & $04(8.7 \%)$ & $44(95.7 \%)$ & $2(4.3 \%)$ \\
\hline
\end{tabular}

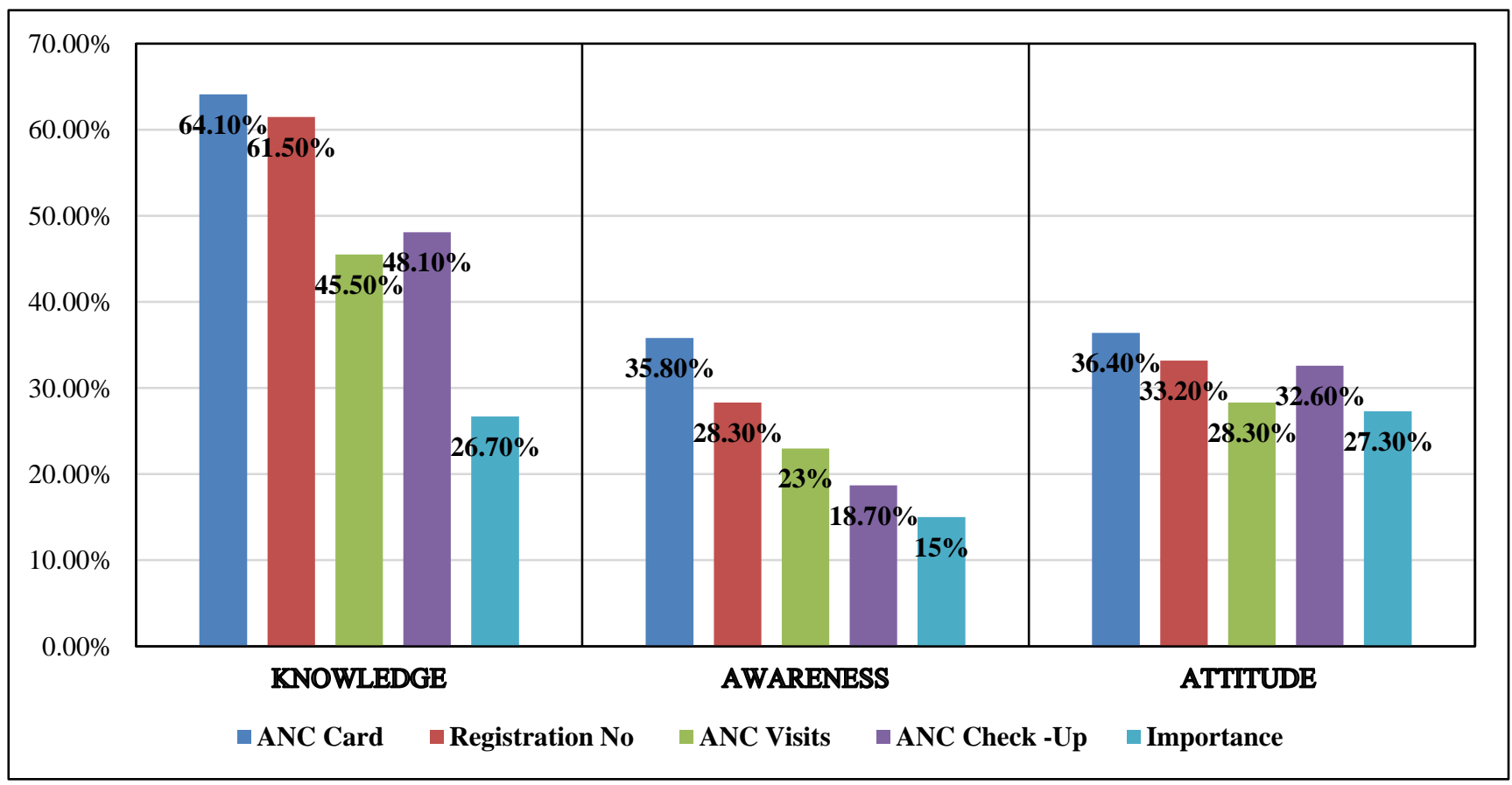

Figure 1: Knowledge, awareness and attitude regarding ANC.

\section{DISCUSSION}

In present study, mean age for respondents was 27 years with age range from 21 to 35 years. Present study showed that not only association between age and knowledge but about awareness and their positive attitude towards ANC practices. A study done by Sanjel S et al, in India had also shown significant association between age and knowledge. Awareness and attitude. ${ }^{8,9}$ In study authors found that educated women had good knowledge, more awareness 
and positive attitude towards ANC, similar findings are seen with the study done by Singh et al, and Lilungulu et al. ${ }^{10,11}$ Comparatively good knowledge, awareness and positive attitude of working women than housewives towards ANC was revealed in present study similar to data given in study done in Malawi. ${ }^{12}$

Overall the women in our study had similar characteristics with other study done in Malawi that ANC women in terms of improvement in knowledge, awareness and attitude towards ANC according to their age, education and occupation. ${ }^{12}$ Multipara women were more concerned about their ANC, regularity in ANC visits as well as medical investigations done, and advice given as required and this may be the result of previous experience of pregnancy. In general, women who are ready to earn more scientific knowledge about ANC, are more aware about their ANC and showed positive attitude towards ANC. Such women also agreed that, it's very important to bring improvement not only in maternal health but also in baby's growth and development.

\section{CONCLUSION}

In conclusion, good scientific knowledge of ANC services, more awareness about ANC check-ups and its regularity and positive attitude towards ANC are important to improve maternal health and baby's development. To improve maternal health services, one should limit barriers among health systems working at all levels. It is a need to find out low risk and high-risk patients regarding the knowledge, awareness and attitude, with the integration of public and private sector concerning ANC services for planning and conduction of programme smoothly.

Funding: No funding sources Conflict of interest: None declared

Ethical approval: The study was approved by the Institutional Ethics Committee

\section{REFERENCES}

1. World Bank. Safe Motherhood- A Review. The Safe Motherhood Initiatives, 1987-2005 World Bank Report. New York: Fam Care Int. 2007;4-7.

2. Ojo. A textbook for midwives in the Trophics. $5^{\text {th }}$ ed. London. Golden and Stoughton; 2004;1-441.

3. Arya A, Mehra N, Mehra JS. Study the knowledge, attitude and practices regarding antenatal care among pregnant women in Haldwani Block, District Naintal (Uttarakhand) Indian. J Med Sci Clin Res. 2017;5(4):20093-102.

4. Adesokan FO. Reproductive health for all ages. AdoEkiti: Faxwell Nigeria. 2010;1-855.

5. Ekabua J, Ekabua K, Njoku C. Proposed framework for making focused antenatal care services accessible: a review of the Nigerian setting. ISRN Obstetr Gynecol. 2011 Dec 29;2011,

6. Homby AS. Oxford Advanced Learners Dictionary of Current English. $6^{\text {th }}$ ed. Oxford University Press; 2006:1433.

7. Igbokwe CC. Knowledge and attitude of pregnant women towards antenatal services in Nsukka Local Government Area of Enugu State, Nigeria. J Res Education Soc. 2012 Apr;3(1).

8. Sanjel S, Ghimire RH, Pun K. Antenatal care practices in Tamang community of hilly area in central Nepal. Kathmandu University Med J. 2011;9(2):57-61.

9. Patel BB, Gurmeet P, Sinalkar DR, Pandya KH, Mahen A, Singh N. A study on knowledge and practices of antenatal care among pregnant women attending antenatal clinic at a Tertiary Care Hospital of Pune, Maharashtra. Med J Dr. DY Patil University. 2016 May 1;9(3):354.

10. Singh D, Lample M, Earnest J. The involvement of men in maternal health care: cross-sectional, pilot case studies from Maligita and Kibibi, Uganda. Reprod Health. 2014 Dec;11(1):68.

11. Lilungulu AG, Matovelo D, Gesase A. Reported knowledge, attitude and practice of antenatal care services among women in Dodoma Municipal. Tanzania. J Pediatr Neonatal Care. 2016;4(1):8.

12. ACCESS End of Project Report. Strengthened Services and Institutions to Expand Focused Antenatal Care and Address Maternal. 2005. Available at: https:/www.mchip.net/sites/default/files/.../complete _ACCESS_EoP_Report_Pdf. March 31, 2010-23.

Cite this article as: Dhavalshankh AG, Dhavalshankh GP, Dixit A. Knowledge, awareness and attitude regarding WHO recommended ANC visits among pregnant women attending antenatal clinic at D.Y. Patil hospital, Kolhapur, Maharashtra, India. Int J Basic Clin Pharmacol 2019;8:689-92. 